\title{
Potential correlates and outcomes of active commuting to school among adolescents
}

\author{
João Martins ${ }^{1 *}$, James F Sallis², Adilson Marques³ , José Diniz $^{3}$, Francisco Carreiro da Costa 3,4 \\ ORIGINAL ARTICLE
}

\begin{abstract}
The present study analysed the prevalence, potential correlates and physical activity (PA), body mass index (BMI), and academic performance outcomes, of active commuting to and from school (ACS), considering the home-to-school distance. A total of 391 Portuguese adolescents (189 boys, aged 14-18 years) completed a questionnaire about their active and passive commuting behaviours; potential correlates and perceived barriers of ACS; PA, BMI and academic performance. Multinomial regressions analyses were performed for 'no walk/cycle', 'one-way commuters' and for 'both-ways commuters' living near ( $<2$ miles) school. The prevalence of one-way and both-ways active commuters decreased as the distance to school increased to more than two miles (66.5\% to $23.5 \%)$. For the 'near group', walking to (47.8\%) and from (55.5\%) school was much more common than cycling $(<1 \%)$. The barrier with the greatest effect for one-way and bothways active commuters was 'distance', followed by 'stuff to carry', 'don't enjoy walking/cycling'. No significant relations were found between walking or cycling one-way or both-ways and total PA, BMI and academic performance. To increase ACS, results suggest interventions promoting bicycling use and addressing multiple perceived barriers, such as 'PA and ACS attitudes', 'stuff to carry', perceptions of 'hot and sweaty' and 'distance'.

Keywords: Active transportation, Physical activity, Obesity, Academic achievement, Psychosocial, Youth.
\end{abstract}

\section{INTRODUCTION}

Active commuting to and from school (ACS), defined as the use of active means such as walking and cycling, is an important contributor of adolescents health, because it is positively associated with higher physical activity (PA) levels (Davison, Werder, \& Lawson, 2008; Faulkner, Buliung, Flora, \& Fusco, 2009; Pont, Ziviani, Wadley, Bennett, \& Abbott, 2009) and a better cardiovascular fitness (Larouche, Saunders, Faulkner, Colley, \& Tremblay, 2014; Lubans, Boreham, Kelly, \& Foster, 2011). However, prevalence of youth ACS is low and has been declining in recent decades in some countries (McDonald, Brown, Marchetti, \& Pedroso, 2011; Pooley, Turnbull, \& Adams, 2005). For example, US data indicate declines in youth ACS from $48 \%$ to $13 \%$ since the late 1960 s
(McDonald et al., 2011); and in the UK from 60\% to $44 \%$ since the mid-1970s (Pooley et al., 2005).

To design effective interventions for promoting youth ACS one important first step is to understand the correlates. Based on ecological models that take a broad view of health behaviour causation (Sallis \& Owen, 2015), several systematic reviews (Davison et al., 2008; Panter, Jones, \& van Sluijs, 2008; Pont et al., 2009) have examined potential correlates of youth ACS from multiple levels of influence, namely, individual, family, school, and social and physical environments. Research suggests that low socioeconomic status (SES) and short distance to school (Davison et al., 2008; Panter et al., 2008; Pont et al., 2009), parental ACS support and perceptions of environment characteristics, social interactions (Davison et al., 2008; Panter et al.,

\footnotetext{
Manuscript received at June 24 ${ }^{\text {th }}$ 2016; Accepted at August 30 2015

${ }^{1}$ Laboratório de Pedagogia, Faculdade de Motricidade Humana e UIDEF, Instituto de Educação, Universidade de Lisboa, Lisboa, Portugal

${ }^{2}$ Department of Family Medicine and Public Health, University of California San Diego, San Diego, California, United States of America

${ }^{3}$ Centro Interdisciplinar de Estudo da Performance Humana, Faculdade de Motricidade Humana, Universidade de Lisboa, Lisboa, Portugal

${ }^{4}$ Faculdade de Educação Física e Desporto, Universidade Lusófona de Humanidades e Tecnologias, Lisboa, Portugal

* Corresponding author: Estrada da Costa, 1499-002 Cruz Quebrada, Lisboa, Portugal. E-mail:

jmartins@fmh.ulisboa.pt
} 
2008), and the presence of adequate walk and bike paths (Panter et al., 2008; Pont et al., 2009), have been positively associated with ACS.

However, mixed results have been found for several other factors (e.g. age, sex, attitudes, perceived safety, street connectivity) (Davison et al., 2008; Panter et al., 2008; Pont et al., 2009) and relatively little is known about the specific perceived barriers of youth ACS (Carlson et al., 2014; Lu et al., 2014). Despite 'distance to school' being the most consistent correlate of youth ACS (Davison et al., 2008; Lu et al., 2014; Panter et al., 2008; Pont et al., 2009), only a limited number of studies have stratified their analysis by the measure (Carlson et al., 2014; Panter, Jones, van Sluijs, \& Griffin, 2011; Van Sluijs et al., 2009).

Regarding the outcomes, youth ACS has been associated with a healthy weight (Faulkner et al., 2009; Østergaard et al., 2012; Saunders, Green, Petticrew, Steinbach, \& Roberts, 2013), and academic performance in a few studies (MartínezGómez et al., 2011; Van Dijk, De Groot, Van Acker, Savelberg, \& Kirschner, 2014), but results are somewhat inconsistent.

This study is well positioned to provide an important contribute to the field because it analyses youth prevalence of ACS in a context where further researcher is needed, such as in European southern countries (Lu et al., 2014; Panter et al., 2008). It will also address the seldom-explored specific barriers of ACS, while stratifying the analysis by distance and ACS patterns, as recommend (Carlson et al., 2014; Panter et al., 2011). Furthermore, the current study will add on the inconsistent and limited evidence about the relationship of ACS with BMI and academic performance.

Therefore, the present study sought (1) to examine the ACS patterns in a sample of Portuguese adolescents who lived near and far from school, (2) to identify the potential correlates of ACS, and (3) to analyze the relationship between the ACS and PA, BMI and academic performance, among those who lived near school. Based on the previous theoretical background, the following hypothesis can be raised: (1) adolescents present low levels of ACS, especially those living far from school; (2) adolescents who live near school and do not walk or cycle rate higher multilevel and specific barriers of ACS then one-way or two-ways active commuters; (3) ACS is significantly and positively related with $\mathrm{PA}$ and academic performance, and inversely related with BMI.

\section{METHODS}

\section{Participants}

Nine public Portuguese schools from Lisbon participated in this cross-sectional study. The schools were selected to optimize variance in adolescents' perceived environmental attributes and SES characteristics. From each school, two classes from $9^{\text {th }}$ grade and two from the $12^{\text {th }}$ grade were randomly selected. The used criteria allowed selecting adolescents studying in the end of the basic and secondary school level, and therefore from distinctive ages. The criteria used for the choice of the adolescents were their participation in PE classes, and not having any health problem. Considering the $9^{\text {th }}$ and $12^{\text {th }}$ grades of all schools, approximately 1400 adolescents were eligible to participate in the survey. Of those, a total of 523 adolescents were invited to participate and completed a questionnaire during PE classes during the spring of 2015. Due to missing data for sex, age, active commuting and home postal codes, 132 questionnaires were eliminated, for a response rate of $74.8 \%$. The final sample was 391 adolescents (189 boys, 202 girls) aged 14-18 years (mean age $16.0 \pm 1.5$ ). Previous to the study, approval from the Portuguese Minister of Education and from the school's principal was obtained. The adolescents' legal guardians provided a written informed consent, and the adolescents volunteered to participate.

\section{Instruments}

\section{Body Mass Index}

Weight and height were self-reported. BMI was calculated $\left(\mathrm{kg} / \mathrm{m}^{2}\right)$, standardized and the BMI $z$-score was obtained.

\section{Family Socioeconomic Status}

Family SES was calculated based on the parental occupation, as described elsewhere (Raudsepp \& Viira, 2000) and as previously used 
in the Portuguese context (Marques, Martins, Santos, Sarmento, \& Carreiro da Costa, 2014; Santos, Esculcas, \& Mota, 2004). Parents' occupation titles were regrouped to classify the participants as low (i.e. manual workers, farmers, and fishermen), middle (i.e. service occupations, such as office clerks, salespeople) or high class (i.e. executives, university-educated specialists and professionals). The higher occupation title from the father or the mother was considered to represent the family SES.

\section{Family education}

Parents' educational level was categorized into low ( $\leq 9$ years of education), middle (10-12 years) and high ( $>12$ years) according to the Portuguese educational system. The higher educational level from the father or the mother was used to define the family education. Similar procedures have been applied in the Portuguese context (Marques et al., 2014; Santos et al., 2004).

\section{Physical activity}

A questionnaire developed by Ledent et al.(1997) was used to assess adolescent's participation in organized PA (i.e. sports activities guided by a teacher/trainer), unorganized PA (i.e. non-guided activities) and school sports (i.e., recreational and/or competitive activities systematically conducted in the context of school sports clubs). Several studies using this questionnaire with Portuguese adolescents were published, as well as evidence of validity and reliability (Marques et al., 2014; Piéron, Telama, Naul, \& Almond, 1997; Santos et al., 2004). The questions used were 'How many times a week do you take part in... (1) organized PA? (2) unorganized PA? (3) school sports?'. By summing the reported number of sessions per week in each context, a 'Total PA' index was obtained.

\section{Academic performance}

Academic performance was measured using adolescents' self-reported grades in Language (Portuguese), Mathematics and Physical Education. In the Portuguese context middle and secondary school grades range from 1 (very poor) to 5 (very good) and from 1 (very poor) to 20 (very good). Therefore, grade $z$-scores were obtained for each subject.

\section{Perceived physical competence}

Lintunen's scale was used to measure adolescents' perceived physical competence (Lintunen, 1990; Marques et al., 2014). Answers were given on a 5 -point Likert scale, and good Cronbach's alpha was obtained for the six items $(\alpha=0.8)$.

\section{Attitude toward physical activity}

The question concerning PA attitude was 'What do you think about practicing PA?'. This reliable question was used in other studies (Delfosse et al., 1997; Marques et al., 2014). Answers were given on a 5 -point scale ranging from 'I dislike it very much' $(=1)$ to 'I like it very much' (=5).

\section{Home-school distance}

Schools' and adolescents' home address postal codes were geocoded using Google maps to determine the travel distance from home to school, a methodology used in prior studies (Villa-Gonza $\square$ lez, Ruiz, \& Chillo $\square n, 2015)$. Only complete postal codes (7 digits in Portugal), identifying the city block and address, were analysed. The distance of the shortest walkable route was considered and recorded to the nearest 0.1 miles. Because adolescents do not typically engage in active travel for more than two miles (McDonald et al., 2011), adolescents were classified as living near $(<2$ miles) and far $(\geq 2$ miles) from the school, as used previously (Carlson et al., 2014).

\section{Home-school commuting}

Adolescents' commuting to school was assessed by question: 'Usually, how do you travel from home to school?' (Matos et al., 2012). The response options were walking, cycling, public transportation, car and motorcycle. For each option, the participants were asked for the time of travelling. The same question and answer options were made regarding commuting from school to home. Time commuted by walking and cycling to and from school were added and termed 'total active commuting time'. Time 
commuted in public transportation, car and motorcycle to and from school were summed and called 'total sedentary commuting time'.

\section{Home-school commuting classification}

Based on their commuting patterns to and from school, participants were categorized as 'noway walk or cycle', 'one-way active commuters' and 'two-ways active commuters'.

Perceived barriers to walking and cycling to and from school

Perceived barriers to walking and cycling to and from school, defined here as a person's estimated level of challenges related to psychological/planning (e.g. get hot/sweaty), safety (e.g. stray dogs) and environmental factors (e.g. distance), were assessed using 17 items of a 4 -point scale $(1=$ Strongly disagree to $4=$ Strongly agree). Test-retest intraclass correlation coefficients (ICC) for the 17 items for 187 U.S. adolescents ranged from .3-.8(Forman et al., 2008). According to Hambleton and Patsula (1998) procedures, the original questionnaire was first translated into Portuguese by one English and Portuguese language official translator, and then back translated by another official translator. To support face validity, a pretest was conducted with 15 Portuguese adolescents where feedback was solicited regarding the meaning of the adapted questionnaire. Test-retest reliability for the 17 items was carried with one-week interval across 107 Portuguese adolescents (ICC ranged from .6.9).

\section{Statistical analysis}

Descriptive statistics were used to characterize the whole sample, and the subgroups living near and far from school. Because of the clustering within schools, between-group comparisons of continuous variables were performed by ANCOVA, using school as covariate. Chi-square tests were used for between-groups comparisons of categorical variables. To identify active commuting potential correlates only those adolescents who lived near the school $(<2$ miles $)$ were included in the analysis, like in previous studies (Carlson et al., 2014). These adolescents were considered to have a realistic opportunity to regularly engage in active commuting. Considering all potential correlates of the independent variable 'homeschool commuting classification' (none, one, or two-way commuters), multinomial regressions analyses were performed. Variables with two and three categories were coded as dummy variables. To examine the relationship between active commuting and total PA, BMI and academic performance, multinomial regressions analyses were also performed. For all models, adjusted odds ratio (OR) with $95 \%$ confidence intervals (CI) were calculated, adjustments for school were performed and the reference category was 'noway walk or cycle'. All statistical analyses were performed using SPSS Statistics 22.0.

\section{RESULTS}

Table 1 shows that about $2 / 3$ of the adolescents lived near ( $<2$ miles) school. Having a family with a low SES $\left[X^{2}(2)=5.987, p=0.05\right]$ and 9 years of education $\left[X^{2}(2)=13.35, p=0.001\right]$ was associated with living near the school. Living far from the school was related with not adopting active commuting behaviours both ways $\left[X^{2}(2)=66.01, p<0.001\right]$. Comparing to the 'far group', those who lived near the school were younger $[F(1,388)=18.021, p<0.001]$, reported more time in ACS $[\mathrm{F}(1,388)=20.981, p<0.001]$, less time in sedentary commuting $[F(1,388)=165.396, p<0.001]$, higher levels of informal PA $[\mathrm{F}(1,388)=4.694, p=0.031]$ and total PA $[\mathrm{F}(1,388)=5.408, p=0.021]$. Those who lived far had significantly $(\mathrm{p}<0.05)$ higher ratings on 10 of 17 specific barriers of ACS and a better academic performance.

Amongst the 'near group' the most common way of commuting to and from school was walking ( $47.8 \%$ and $55.5 \%$, respectively), public transport $(21.3 \%$ and $24.6 \%)$ and car $(22.8 \%$ and $10.7 \%$ ) (table 2). Fewer than $2 \%$ of the adolescents used either the bicycle or motorcycle. Public transports were most used to commute to and from school (42.0\% and $53.8 \%$ ) by the 'far group' adolescents, followed by car $(36.1 \%$ and $18.5 \%)$. 
Table 1

Descriptive characteristics of adolescents classified as living near ( $<2$ miles) and far ( $>2$ miles) from the school

\begin{tabular}{|c|c|c|c|c|}
\hline Variables & Total n (\%) & Near n (\%) & Far n (\%) & $p$ \\
\hline \multicolumn{5}{|l|}{$\operatorname{Sex}^{\mathrm{a}}$} \\
\hline Boys & $189(48.3)$ & $123(45.2)$ & $66(55.5)$ & \multirow{2}{*}{0.062} \\
\hline Girls & $202(51.7)$ & $149(54.8)$ & $53(44.5)$ & \\
\hline \multicolumn{5}{|l|}{ Family socioeconomic status ${ }^{a}$} \\
\hline Low & $63(16.3)$ & $52(19.3)$ & $11(9.4)$ & \multirow{3}{*}{0.05} \\
\hline Middle & $166(42.9)$ & $110(40.7)$ & $56(47.9)$ & \\
\hline High & $187(40.4)$ & $108(40.0)$ & $50(42.7)$ & \\
\hline \multicolumn{5}{|l|}{ Family education ${ }^{a}$} \\
\hline 9 years or less (low) & $67(17.3)$ & $59(21.9)$ & $8(6.8)$ & \multirow{3}{*}{0.001} \\
\hline $10-12$ years (middle) & $98(25.3)$ & $66(24.5)$ & $32(27.1)$ & \\
\hline More than 12 years (high) & $222(57.4)$ & $144(53.5)$ & $78(66.1)$ & \\
\hline \multicolumn{5}{|l|}{ Home-school commuting classification ${ }^{\mathrm{a}}$} \\
\hline No-way walk or cycle & $182(46.5)$ & $91(35.5)$ & $91(76.5)$ & \multirow{3}{*}{0.000} \\
\hline One way active commuters & $70(17.9)$ & $54(19.9)$ & $16(13.4)$ & \\
\hline \multirow[t]{2}{*}{ Two-ways active commuters } & $139(35.6)$ & $127(46.6)$ & $12(10.1)$ & \\
\hline & Mean \pm SD & Mean \pm SD & Mean \pm SD & $p$ \\
\hline $\mathrm{Age}^{\mathrm{b}}$ & $16.02 \pm 1.53$ & $15.78 \pm 1.5$ & $16.55 \pm 1.36$ & 0.000 \\
\hline BMI z-score ${ }^{b}$ & $0.01 \pm 1.01$ & $0.05 \pm 1.00$ & $-0.05 \pm 0.91$ & 0.316 \\
\hline Distance home-school (miles) ${ }^{\mathrm{b}}$ & $3.05 \pm 3.10$ & $1.52 \pm 0.81$ & $6.54 \pm 3.54$ & 0.000 \\
\hline \multicolumn{5}{|l|}{ Home-school commuting time (minutes) } \\
\hline Active commuting home-school time & $4.73 \pm 7.12$ & $5.71 \pm 7.41$ & $2.48 \pm 5.84$ & 0.000 \\
\hline Active commuting school-home time & $6.44 \pm 9.01$ & $7.76 \pm 9.56$ & $3.41 \pm 6.97$ & 0.000 \\
\hline Total active commuting time & $11.17 \pm 14.72$ & $13.47 \pm 15.20$ & $5.89 \pm 12.05$ & 0.000 \\
\hline Sedentary commuting home-school time & $11.05 \pm 14.01$ & $6.15 \pm 8.35$ & $22.24 \pm 17.54$ & 0.000 \\
\hline Sedentary commuting school-home time & $11.72 \pm 15.38$ & $6.10 \pm 9.25$ & $24.56 \pm 18.60$ & 0.000 \\
\hline Total sedentary commuting time & $22.76 \pm 28.71$ & $12.25 \pm 16.98$ & $46.80 \pm 35.02$ & 0.000 \\
\hline \multicolumn{5}{|l|}{ Physical activity (sessions/week) ${ }^{\mathrm{b}}$} \\
\hline Informal PA practice & $2.41 \pm 2.21$ & $2.58 \pm 2.25$ & $2.04 \pm 2.08$ & 0.031 \\
\hline Formal PA practice & $1.69 \pm 2.00$ & $1.74 \pm 2.07$ & $1.58 \pm 1.83$ & 0.336 \\
\hline School sport & $0.31 \pm 0.79$ & $0.35 \pm 0.84$ & $0.20 \pm 0.66$ & 0.080 \\
\hline Total PA & $4.38 \pm 3.48$ & $4.64 \pm 3.71$ & $3.80 \pm 2.84$ & 0.021 \\
\hline \multicolumn{5}{|l|}{ Academic performance ${ }^{b}$} \\
\hline Language $z$-score & $-0.02 \pm 1.00$ & $-0.18 \pm 0.91$ & $0.49 \pm 1.06$ & 0.000 \\
\hline Mathematics z-score & $-0.02 \pm 1.00$ & $-0.15 \pm 0.97$ & $0.38 \pm 0.97$ & 0.000 \\
\hline Physical Education z-score & $-0.03 \pm 1.00$ & $-0.14 \pm 0.98$ & $0.37 \pm 0.93$ & 0.000 \\
\hline \multicolumn{5}{|l|}{ Psychological variables $(1-5)^{\mathrm{b}}$} \\
\hline Perceived physical competence & $3.56 \pm 0.73$ & $3.58 \pm 0.72$ & $3.51 \pm 0.74$ & 0.478 \\
\hline PA attitude & $3.90 \pm 1.01$ & $3.91 \pm 1.02$ & $3.87 \pm 0.98$ & 0.644 \\
\hline \multicolumn{5}{|l|}{ Perceived barriers to walk and cycle to/from school $(1-4)^{\mathrm{b}}$} \\
\hline There are no sidewalks or bike lanes & $2.15 \pm 0.97$ & $2.02 \pm 0.93$ & $2.44 \pm 1.01$ & 0.000 \\
\hline The route is boring & $2.05 \pm 0.82$ & $2.03 \pm 0.81$ & $2.10 \pm 0.84$ & 0.382 \\
\hline The route does not have good lighting & $1.87 \pm 0.76$ & $1.80 \pm 0.74$ & $2.03 \pm 0.77$ & 0.004 \\
\hline There are one or more dangerous crossings & $2.63 \pm 0.93$ & $2.53 \pm 0.92$ & $2.84 \pm 0.92$ & 0.001 \\
\hline I get too hot and sweaty & $2.13 \pm 0.90$ & $2.05 \pm 0.86$ & $2.33 \pm 0.95$ & 0.010 \\
\hline No other teens walk or bike & $1.77 \pm 0.86$ & $1.65 \pm 0.79$ & $2.04 \pm 0.96$ & 0.000 \\
\hline It's not considered cool to walk or bike & $1.51 \pm 0.72$ & $1.53 \pm 0.70$ & $1.48 \pm 0.74$ & 0.509 \\
\hline I have too much stuff to carry & $2.73 \pm 0.91$ & $2.67 \pm 0.92$ & $2.87 \pm 0.87$ & 0.030 \\
\hline It's easier to drive or get driven there & $2.83 \pm 0.96$ & $2.80 \pm 0.98$ & $2.89 \pm 0.93$ & 0.321 \\
\hline It involves too much planning ahead & $1.87 \pm 0.85$ & $1.82 \pm 0.86$ & $1.99 \pm 0.82$ & 0.060 \\
\hline There is nowhere to leave a bike safely & $2.37 \pm 0.97$ & $2.32 \pm 0.99$ & $2.48 \pm 0.93$ & 0.114 \\
\hline There are stray dogs & $1.89 \pm 0.85$ & $1.87 \pm 0.87$ & $1.94 \pm 0.81$ & 0.223 \\
\hline It's too far & $2.31 \pm 1.06$ & $2.00 \pm 0.94$ & $3.03 \pm 0.97$ & 0.000 \\
\hline I would have to walk/bike through places that were unsafe & & & & \\
\hline because of crime or things sometimes related to crime & $2.05 \pm 0.91$ & $2.00 \pm 0.92$ & $2.17 \pm 0.88$ & 0.056 \\
\hline I don't enjoy walking or biking to school & $2.09 \pm 0.91$ & $2.01 \pm 0.89$ & $2.29 \pm 0.94$ & 0.006 \\
\hline There are too many hills & $2.01 \pm 1.07$ & $1.88 \pm 0.93$ & $2.32 \pm 1.00$ & 0.000 \\
\hline There is too much traffic & $2.37 \pm 0.94$ & $2.18 \pm 0.88$ & $2.82 \pm 0.93$ & 0.000 \\
\hline
\end{tabular}

Abbreviations: SD, standard deviation; BMI, body mass index, PA, physical activity; MVPA, Moderate to vigorous physical

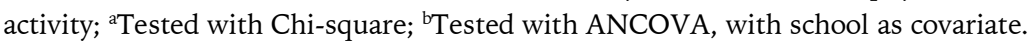


Table 2

Mode of transport to and from school of adolescents classified as living near $(<2$ miles) and far ( $>2$ miles) from the school

\begin{tabular}{lcccccc}
\hline \multirow{2}{*}{ Mode of transport } & \multicolumn{2}{c}{ Total } & \multicolumn{2}{c}{ Near } & \multicolumn{2}{c}{ Far } \\
\cline { 2 - 7 } & Home/School & School/Home & Home/School & School/Home & Home/School & School/Home \\
\cline { 2 - 7 } & $\mathbf{n}(\%)$ & $\mathbf{n}(\%)$ & $\mathbf{n}(\%)$ & $\mathbf{n}(\%)$ & $\mathbf{n}(\%)$ & $\mathbf{n}(\%)$ \\
\hline Walk & $143(36.6)$ & $168(43.0)$ & $130(47.8)$ & $151(55.5)$ & $13(10.9)$ & $17(14.3)$ \\
Bicycle & $2(0.5)$ & $1(0.3)$ & $2(0.7)$ & $1(0.4)$ & $0(0)$ & $0(0)$ \\
Public transport & $108(27.6)$ & $131(33.5)$ & $58(21.3)$ & $67(24.6)$ & $50(42.0)$ & $64(53.8)$ \\
Car & $105(26.9)$ & $51(13.0)$ & $62(22.8)$ & $29(10.7)$ & $43(36.1)$ & $22(18.5)$ \\
Motorcycle & $5(1.3)$ & $3(0.8)$ & $2(0.7)$ & $0(0)$ & $3(2.5)$ & $3(2.5)$ \\
Mixed - active and passive & $24(6.1)$ & $32(8.2)$ & $15(5.5)$ & $22(8.1)$ & $9(7.6)$ & $10(8.4)$ \\
Mixed - only passive & $4(1.0)$ & $5(1.3)$ & $3(1.1)$ & $2(0.7)$ & $1(0.8)$ & $3(2.5)$ \\
Total & $391(100.0)$ & $391(100.0)$ & $272(100.0)$ & $272(100.0)$ & $119(100.0)$ & $119(100.0)$ \\
\hline
\end{tabular}

Note: Mixed - active and passive, means selecting at least one active and one sedentary transport mode (e.g. walking and public transport); Mixed - only passive, means selecting at least two sedentary transport modes (e.g. car and public transport).

Table 3

Models for correlates of one-way and both-ways active commuters that lived near $(<2$ miles) the school $(n=272)$.

\begin{tabular}{|c|c|c|c|c|}
\hline \multirow{3}{*}{ Predictors } & \multicolumn{4}{|c|}{ Home-school commuting classification } \\
\hline & \multicolumn{2}{|c|}{ Walk or cycle one-way } & \multicolumn{2}{|c|}{ Walk or cycle both-ways } \\
\hline & $\begin{array}{l}\text { Adjusted OR } \\
(95 \% \mathrm{CI})\end{array}$ & $p$ & $\begin{array}{l}\text { Adjusted OR } \\
(95 \% \mathrm{CI})\end{array}$ & $p$ \\
\hline \multicolumn{5}{|l|}{ Sex } \\
\hline Male & 1.00 (ref) & & 1.00 (ref) & \\
\hline Female & $1.86(0.70-4.94)$ & 0.216 & $1.10(0.43-2.82)$ & 0.842 \\
\hline \multicolumn{5}{|l|}{ Family SES } \\
\hline Low & 1.000 (ref) & & 1.000 (ref) & \\
\hline Middle & $0.25(0.06-1.07)$ & 0.061 & $0.35(0.09-1.35)$ & 0.129 \\
\hline High & $0.33(0.07-1.69)$ & 0.184 & $0.23(0.05-1.07)$ & 0.061 \\
\hline \multicolumn{5}{|l|}{ Family education } \\
\hline Low (9 years or less) & 1.00 (ref) & & 1.000 (ref) & \\
\hline Middle (10-12 years) & $0.45(0.11-1.86)$ & 0.269 & $0.71(0.19-2.56)$ & 0.595 \\
\hline High (More than 12 years) & $1.14(0.24-5.44)$ & 0.868 & $2.47(0.59-1.40)$ & 0.217 \\
\hline Age & $0.73(0.50-1.08)$ & 0.114 & $0.80(0.56-1.13)$ & 0.205 \\
\hline BMI z-score & $0.62(0.38-1.01)$ & 0.056 & $0.60(0.40-0.91)$ & 0.017 \\
\hline \multicolumn{5}{|l|}{ Psychological variables } \\
\hline Perceived physical competence & $0.49(0.21-1.15)$ & 0.101 & $0.61(0.27-1.35)$ & 0.219 \\
\hline PA attitude & $2.46(1.34-4.54)$ & 0.004 & $1.31(0.79-2.18)$ & 0.292 \\
\hline \multicolumn{5}{|l|}{ Perceived barriers } \\
\hline There are no sidewalks or bike lanes & $0.65(0.37-1.16)$ & 0.148 & $0.71(0.42-1.22)$ & 0.218 \\
\hline The route is boring & $0.76(0.36-1.59)$ & 0.461 & $0.75(0.37-1.52)$ & 0.421 \\
\hline The route does not have good lighting & $1.11(0.54-2.28)$ & 0.782 & $0.69(0.35-1.35)$ & 0.272 \\
\hline There are one or more dangerous crossings & $0.94(0.53-1.78)$ & 0.976 & $0.80(0.44-1.43)$ & 0.448 \\
\hline I get too hot and sweaty & $1.98(1.04-3.76)$ & 0.037 & $1.26(0.68-2.33)$ & 0.467 \\
\hline No other teens walk or bike & $1.28(0.63-2.59)$ & 0.490 & $1.01(0.49-2.05)$ & 0.978 \\
\hline It's not considered cool to walk or bike & $1.10(0.49-2.00)$ & 0.981 & $2.07(1.00-4.30)$ & 0.051 \\
\hline I have too much stuff to carry & $0.56(0.31-0.99)$ & 0.046 & $0.47(0.28-0.82)$ & 0.008 \\
\hline It's easier to drive or get driven there & $1.12(0.61-2.05)$ & 0.715 & $0.49(0.28-0.86)$ & 0.012 \\
\hline It involves too much planning ahead & $0.92(0.51-1.64)$ & 0.770 & $1.17(0.67-2.04)$ & 0.583 \\
\hline There is nowhere to leave a bike safely & $1.04(0.58-1.85)$ & 0.897 & $1.17(0.67-2.04)$ & 0.592 \\
\hline There are stray dogs & $1.39(0.69-2.81)$ & 0.355 & $1.95(0.98-3.88)$ & 0.057 \\
\hline It's too far & $0.48(0.25-0.89)$ & 0.021 & $0.30(0.16-0.58)$ & 0.000 \\
\hline $\begin{array}{l}\text { I would have to walk/bike through places that were unsafe } \\
\text { because of crime or things sometimes related to crime }\end{array}$ & $1.13(0.60-2.11)$ & 0.711 & $1.37(0.73-2.54)$ & 0.324 \\
\hline I don't enjoy walking or biking to school & $0.49(0.25-0.97)$ & 0.040 & $0.47(0.24-0.92)$ & 0.028 \\
\hline There are too many hills & $1.41(0.73-2.72)$ & 0.303 & $1.15(0.63-2.09)$ & 0.655 \\
\hline There is too much traffic & $1.14(0.60-2.15)$ & 0.693 & $1.03(0.56-1.91)$ & 0.920 \\
\hline
\end{tabular}

Abbreviations: OR, odds ratio; BMI, body mass index, PA, physical activity; Reference category is no-way walk or cycle; Models adjusted for schools. 
Table 4

Models for outcomes of one-way and both-ways active commuters that lived near $(<2$ miles $)$ the school $(n=272)$.

\begin{tabular}{|c|c|c|c|c|}
\hline \multirow{3}{*}{ Predictors } & \multicolumn{4}{|c|}{ Home-school commuting classification } \\
\hline & \multicolumn{2}{|c|}{ Walk or cycle one-way } & \multicolumn{2}{|c|}{ Walk or cycle both-ways } \\
\hline & Adjusted OR (95\% CI) & $p$ & Adjusted OR (95\% CI) & $p$ \\
\hline BMI z-score & $0.81(0.57-1.12)$ & 0.304 & $1.00(0.76-1.32)$ & 0.998 \\
\hline Total PA (sessions/week) & $1.10(0.98-1.23)$ & 0.097 & $1.06(0.97-1.17)$ & 0.213 \\
\hline \multicolumn{5}{|l|}{ Academic performance } \\
\hline Language $z$-score & $1.40(0.37-5.29)$ & 0.627 & $1.56(0.49-4.98)$ & 0.449 \\
\hline Mathematics z-score & $1.28(0.26-6.32)$ & 0.759 & $1.04(0.26-4.15)$ & 0.955 \\
\hline Physical Education z-score & $1.30(0.31-4.78)$ & 0.776 & $0.55(0.17-1.79)$ & 0.318 \\
\hline
\end{tabular}

Abbreviations: OR, odds ratio; BMI, body mass index, PA, physical activity.

Reference category is no-way walk or cycle.

Models adjusted for sex, age, family socioeconomic status and education, and schools.

Table 3 presents the adjusted multinomial regressions analyses models for the correlates of ACS of 'one-way commuters' and 'both-ways commuters' that lived near the school. Adjustments for schools were considered. The barrier with the greatest effect was 'It's too far,' with OR's of .48 (one-way active commuters) and .30 (two-ways active commuters). Those who walked or cycled either one way or both ways had significantly lower ratings of 'too much stuff to carry' and 'I don't enjoy walking/biking'. Bothways active commuters disagree that 'it's easier get driven' to school $(\mathrm{OR}=.49)$. Those who walked or cycled only one-way had a higher PA attitude. Conversely, 'getting hot and sweaty' was rated higher by those who walked or cycled one-way. Lastly, active commuting both ways was significantly associated with having a lower BMI.

No significant $(p>0.05)$ relations were found between walk or cycle one-way or both-ways and the outcomes BMI, total PA and academic performance in Language, Mathematics and Physical Education (Table 4). Models were adjusted for demographic variables and schools.

\section{DISCUSSION}

The present study analysed the prevalence, correlates and outcomes of ACS among a sample of Portuguese adolescents, by taking into account the home school distance. It was found that the prevalence of ACS was low and declined as the distance to school increased; 'no walk or cycle' adolescents reported facing more multilevel and specific barriers of ACS; and ACS was not related with PA, BMI and academic performance outcomes. These results support the first and second study hypothesis but not the third.
About $2 / 3$ of these Portuguese adolescents lived within 2 miles of school, a reasonable walking and cycling distance (McDonald et al., 2011). This compared to about $50 \%$ in US studies (McDonald et al., 2011). Other European studies have found that about $50 \%$ and $65 \%$ of youth lived within, respectively, 1 mile (Van Sluijs et al., 2009) and 1.4 miles (Panter et al., 2011), suggesting that more US youth live farther from their schools. Since distance is the most consistent barrier of ACS (Davison et al., 2008; Lu et al., 2014; Pont et al., 2009), this might help to explain the higher prevalence of youth ACS found in this and other European studies (Pooley et al., 2005; Van Sluijs et al., 2009) when compared to US studies, where fewer than $15 \%$ of youth are walking and cycling to school (McDonald et al., 2011). In the present study, regardless of distance to school, the prevalence of one-way and both-ways active commuters was $54 \%$, which supports previous Portuguese research conducted in the North region of Portugal, where the prevalence of ACS varied between $52.6 \%$ (Mota et al., 2007) and $70 \%$ (Santos et al., 2009). However, when considering a representative sample of Portuguese adolescents, the prevalence of ACS was only about $35 \%$ (Loureiro \& Matos, 2014), which might be related to the inclusion of more diverse living contexts such as rural areas (Panter et al., 2008; Pont et al., 2009).

This study demonstrated there is a marked decrease in the proportion of one-way and bothways active commuters as the distance to school increases to more than two miles $(66.5 \%$ to $23.5 \%)$. Though the overall prevalence of ACS was high among adolescents in the 'near group', almost all of them were walking. Only about $2 \%$ 
of the adolescents reported cycling to school, indicating this is an opportunity for intervention. Low levels $(<5 \%)$ of cycling to school have been previously reported in the Portuguese context (Loureiro \& Matos, 2014; Santos, Oliveira, Ribeiro, \& Mota, 2009). Generally, the main barrier to cycling is concerns about traffic safety (Lu et al., 2014; Panter et al., 2008), so some combination of protected bicycle facilities, promotional activities, and education of cyclists and motorists could be evaluated. The present study demonstrates there is much more room for ACS improvement among Portuguese adolescents, particularly among those subgroups who lived within 2 miles of school but do not walk or cycle $(35.5 \%)$, or only do it one-way (19.9\%); and among the sedentary commuters who live farther than 2 miles (76.5\%). Bicycling could be an option for many students who lived more than 2 miles, if cycling conditions were safer.

Comparing to the 'near group', the 'far group' rated highly the barriers such as 'distance', 'lack of sidewalks and bike lanes', 'dangerous crossings' and 'too much traffic', and they spent much more time in sedentary commuting to and from school. Since sedentary behaviours are usually high in youth, tend to track into adulthood and can be negatively related to health (Chinapaw, Proper, Brug, van Mechelen, \& Singh, 2011), it is important to reduce the sedentary commuting to and from school. The identified barriers by the 'far group' have been found in previous studies (Lu et al., 2014) and might be taken into account for finding alternative strategies to reduce their sedentary commuting time. Note that the majority of these significant barriers were related to concerns about traffic safety. Thus, interventions to improve safety of walking and bicycling to school need to be developed in collaboration with transportation professionals.

When considering only the 'near group' analyses (table 3), demographic variables were not important correlates of ACS, but several specific beliefs were significant, such as positive attitudes towards PA and ACS. This result suggests that a generalized positive attitude about PA may predispose Portuguese youth to
ACS. This result is contradictory to some previous research (Davison et al., 2008). However, it supports Panter's et al.(2008) theoretical framework, where it is hypothesized that youth with positive attitude towards PA and walking may consequently perceive the environment as more suitable for active commuting. The attitude factors related to PA and ACS warrant therefore greater research.

Most significant barriers were related to both one-way and two-way active commuting, providing an internal replication and enhancing confidence in the findings. Thus, the barriers with the strongest evidence were 'too far' and 'too much stuff to carry'. The barrier of 'don't enjoy' active commuting had also an important effect size, reducing the rate of both-way ACS by about $50 \%$. The barrier of 'get hot and sweaty' was rated significantly higher by one-way active commuters, suggesting it does not prevent them from walking or cycling but makes active commuting less pleasant or enjoyable.

Present findings can be the basis of interventions targeting adolescents who live within walking or cycling distance that can be evaluated. Educational campaigns could address the 'don't enjoy' barrier and build positive attitudes about PA in general. An educational program could help change perceptions of reasonable walking and cycling distance. Interventions to make walking, and especially cycling, safer could expand the range for ACS. As tablet computers become more common educational tools, the barrier of 'too much stuff to carry' could be reduced, making active commuting more feasible. Another option is to provide lockers so adolescents could store some of their books overnight. The barrier of 'hot and sweaty', which prior studies indicated is a bigger concern for girls than boys (Martins, Marques, Sarmento, \& Carreiro da Costa, 2015), could be addressed by making time, showers and lockers available to adolescents.

Regarding the outcomes, it was surprising that ACS was not related to total PA. This result is inconsistent with many studies that have shown ACS contributes to total PA (Davison et al., 2008; Faulkner et al., 2009; Pont et al., 2009). Though present measures of PA have been 
validated among Portuguese youth (Piéron et al., 1997; Santos et al., 2004), they did not really represent total PA because three items were about leisure PA. Evidence about the relation of active commuting to BMI is inconsistent (Faulkner et al., 2009; Saunders et al., 2013). That inconsistency was also seen in present results with BMI not related to active commuting in one analysis (Table 4) but significantly related in another (Table 3). The present inconsistency may be explained by the presence of different variables in the models (i.e. psychological and perceived barriers were not included in table 4 analyses). Though many studies have documented that physically active and fit youth have better academic performance (Castelli et al., 2014), few studies have examined the role of ACS in academic performance. The finding of this study that ACS was not related with academic performance is an accordance with one study (Van Dijk et al., 2014) but not with another one (Martínez-Gómez et al., 2011), that found a positive association only in girls. A potential explanation of the lack of findings of analysed outcomes is that adolescents reported their 'usual' methods of commuting to and from school. Thus, the frequency of commuting was unknown, and variability was limited, thus reducing statistical power. Lack of standard methods of measuring commuting to school has been identified as a limitation of research in this area (Davison et al., 2008).

A strength of the present study was assessing correlates of ACS only among those living within a reasonable distance, which allowed identifying correlates relevant to the target audience. Another strength was focusing on an important and seldom explored topic in the literature, such as the relationship between ACS and academic performance. Conducting a study in a southern European country, and specifically in the most populated zone of Portugal, was important because further research on youth ACS prevalence, correlates and outcomes is needed in distinct contexts. To the best of our knowledge, previous national studies have been mainly conducted in the north region of Portugal (Mota et al., 2007; Santos et al., 2009). Almost all the measures used had some evidence of reliability and validity, but a limitation was that all measures were self-reported. Not all adolescents could be included in analyses because their addresses could not be geocoded, and the size sample was substantially reduced. Finally, this study was cross-sectional and cause-effect relationships cannot be identified.

\section{CONCLUSIONS}

The present study highlighted that the prevalence of ACS was high among those Portuguese adolescents living near and low among those living far from school. The "near group' ACS prevalence could, however, be further improved by promoting bicycle use and by addressing multiple barriers, such as 'PA and ACS attitudes', 'stuff to carry', perceptions of 'hot and sweaty' and of 'distance'. Despite no associations have been found between ACS, total $\mathrm{PA}$, healthy weight and academic performance in this study, further research stratifying analyses by distance, measuring the frequency of ACS, including objective measures of total PA, and adopting a longitudinal design should be considered. Future studies should also consider the parents' role on youth ACS, and the season of the year.

Acknowledgements:
The authors thank the adolescents for their
participation in the study

Conflicts of interest:

Nothing to declare

\section{Funding:}

Nothing to declare

\section{REFERÊNCIAS}

Carlson, J., Sallis, J., Kerr, J., Conway, T., Cain, K., Frank, L., \& Saelens, B. (2014). Built environment characteristics and parent active transportation are associated with active travel to school in youth age 12-15. British Journal of Sports Medicine, 48, 1634-1639.

Castelli, D., Centeio, E., Hwang, J., Barcelona, J., Glowacki, E., Calvert, H., \& Nicksic, H. (2014). VII. The history of physical activity and academic performance research: Informing the future. 
Monographs of the Society for Research in Child Development, 79(4), 119-148.

Chinapaw, M., Proper, K., Brug, J., van Mechelen, W., \& Singh, A. (2011). Relationship between young peoples' sedentary behaviour and biomedical health indicators: a systematic review of prospective studiesobr_865 621..632. Obesity Reviews, 12, e621-e632.

Davison, K., Werder, J., \& Lawson, C. (2008). Children's Active Commuting to School: Current Knowledge and Future Directions. Preventive Chronic Disease, 5(3), http://www.cdc.gov/pcd/issues/2008/Jul/pdf/2 007_0075.pdf Acessed September 2015.

Delfosse, C., Ledent, M., Carreiro da Costa, F., Almond, L., Cloes, M., \& Piéron, M. (1997). Les attitudes de jeunes européens à l'égard de l'école et du cours d'éducation physique. Sport, 159/160, 96-105.

Faulkner, G., Buliung, R., Flora, P., \& Fusco, C. (2009). Active school transport, physical activity levels and body weight of children and youth: A systematic review. Preventive Medicine, 48, 3-8.

Forman, H., Kerr, J., Norman, G., Saelens, B., Durant, N., Harris, S., \& Sallis, J. (2008). Reliability and validity of destination-specific barriers to walking and cycling for youth. Preventive Medicine, 46(4), 311-316.

Hambleton, R., \& Patsula, L. (1998). Adapting tests for use in multiple languages and cultures. Social Indicators Research, 45, 153-171.

Larouche, R., Saunders, T., Faulkner, G., Colley, R., \& Tremblay, M. (2014). Associations between active school transport and physical activity, body composition and cardiovascular fitness: a systematic review of 68 studies. Journal of Physical Activity and Health, 11 (1), 206-227.

Ledent, M., Cloes, M., Telema, R., Almond, L., Diniz, J., \& Piéron, M. (1997). Participation des jeunes européens aux activités physique et sportives. Sports, 159/160, 61-71.

Lintunen, T. (1990). Perceived physical competence scale for children. In A. Ostrow (Ed.), Directory of psychological tests in the sport and exercise sciences (pp. 140). Morgantown, WV: Fitness Information Technology.

Loureiro, N., \& Matos, M. (2014). Why don't they walk or cycle? Reflections on active home-school transportation among Portuguese adolescents: the role of environmental perceptions. Urban, Planning and Transport Research, 2(1), 265-273.

Lu, W., McKyer, J., Lee, C., Goodson, P., Ory, M., \& Wang, S. (2014). Perceived barriers to children's active commuting to school: a systematic review of empirical, methodological and theoretical evidence. 11, 140. doi: 10.1186/s12966-0140140-x

Lubans, D., Boreham, C., Kelly, P., \& Foster, C. (2011). The relationship between active travel to school and health-related fitness in children and adolescents: a systematic review. International
Journal of Behavioral Nutrition and Physical Activity, 8(5). doi: 10.1186/1479-5868-8-5.

Marques, A., Martins, J., Santos, F., Sarmento, H., \& Carreiro da Costa, F. (2014). Correlates of school sport participation: A cross sectional study in urban Portuguese adolescents. Science \& Sports, 29, e31-e38. doi: 10.1016/j.scispo.2013.07.012

Martínez-Gómez, D., Ruiz, J., Gómez-Martínez, S., Chillón, P., Rey-López, J., Díaz, L., . . Marcos, A. (2011). Active commuting to school and cognitive performance in adolescents. The AVENA study. Archives of Pediatrics \& Adolescent Medicine, 165(4), 300-305.

Martins, J., Marques, A., Sarmento, H., \& Carreiro da Costa, F. (2015). Adolescents' perspectives on the barriers and facilitators of physical activity: a systematic review of qualitative studies. Health Education Research. doi: 10.1093/her/cyv042

Matos, M., Simões, C., Tomé, G., Camacho, I., Ferreira, M., Ramiro, L., . . . Equipa Aventura Social. (2012). A saúde dos adolescentes portugueses: Relatório do estudo HBSC 2010 [Social Adventure \& health. The health of adolescents]. Cruz-Quebrada: Faculdade de Motricidade Humana.

McDonald, N., Brown, A., Marchetti, L., \& Pedroso, M. (2011). U.S. school travel, 2009. An Assessment of trends. American Journal of Preventive Medicine, 41(2), 146-151.

Mota, J., Gomes, H., Almeida, M., Ribeiro, J., Carvalho, J., \& Santos, M. (2007). Active versus passive transportation to school - differences in screen time, socio-economic position and perceived environmental characteristics in adolescent girls. Annals of Human Biology, 34(3), 273-282.

Østergaard, L., Grøntved, A., Børrestad, L., Froberg, K., Gravesen, M., \& Andersen, L. (2012). Cycling to School Is Associated With Lower BMI and Lower Odds of Being Overweight or Obese in a Large Population-Based Study of Danish Adolescents. Journal of Physical Activity and Health, 9, 617-625.

Panter, J., Jones, A., \& van Sluijs, E. (2008). Environmental determinants of active travel in youth: A review and framework for future research. International Journal of Behavioral Nutrition and Physical Activity, 5(34). doi: 10.1186/1479-5868-5-34

Panter, J., Jones, A., van Sluijs, E., \& Griffin, S. (2011). The influence of distance to school on the associations between active commuting and physical activity. Pediatric Exercise Science, 23, 7286.

Piéron, M., Telama, R., Naul, R., \& Almond, L. (1997). Étude du style de vie d'adolescents européens. Considérations théoriques, objectifs et méthodologie de recherche. Sports, 159/160, 4350.

Pont, K., Ziviani, J., Wadley, D., Bennett, S., \& Abbott, R. (2009). Environmental correlates of children's active transportation: A systematic literature review. Health \& Place, 15, 849-862. 
Pooley, C., Turnbull, J., \& Adams, M. (2005). The journey to school in Britain since the 1940s: continuity and change. Area, 37(1), 43-54.

Raudsepp, L., \& Viira, R. (2000). Sociocultural correlates of physical activity in adolescents. Pediatric Exercise Science, 12, 51-60.

Sallis, J., \& Owen, N. (2015). Ecological models of health behavior. In K. Glanz, B. Rimer, \& K. Viswanath (Eds.), Health behavior. Theory, Research and Practice (5 ed.). San Francisco, CA: JosseyBass.

Santos, P., Esculcas, C., \& Mota, J. (2004). The relationship between socioeconomic status and adolescents' organized and nonorganized physical activities. Pediatric Exercise Science, 16, 210-218.

Santos, P., Oliveira, J., Ribeiro, J., \& Mota, J. (2009). Active travel to school, BMI and participation in organised and non-organised physical activity among Portuguese adolescents. Preventive Medicine, 49, 497-499.
Saunders, L., Green, J., Petticrew, M., Steinbach, R., \& Roberts, H. (2013). What are the health benefits of active travel? A systematic review of trials and cohort studies. PloS One, 8(8), e69912. doi: 10.1371/journal.pone.0069912

Van Dijk, M., De Groot, R., Van Acker, F., Savelberg, H., \& Kirschner, P. (2014). Active commuting to school, cognitive performance, and academic achievement: an observational study in Dutch adolescents using accelerometers. BMC Public Health, 14, 799.

Van Sluijs, E., Fearne, V., Mattocks, C., Riddoch, C., Griffin, S., \& Ness, A. (2009). The contribution of active travel to children's physical activity levels: Cross-sectional results from the ALSPAC study. Preventive Medicine, 48, 519-524.

Villa-Gonza $\square$ lez, E., Ruiz, J., \& Chillo $\square$ n, P. (2015). Associations between active commuting to school and health-related physical fitness in spanish school-aged children: A cross-sectional study. International Journal of Environmental Research and Public Health, 12, 10362-10373. 